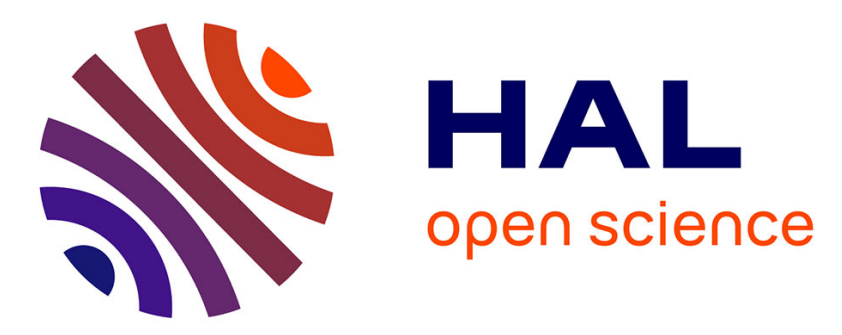

\title{
Carrier lifetime influence on clamped silicon wafer resonance by PTA effect
}

C. Chapus, F. Augereau, J. Podlecki, Gaëtan Lévêque, A. Foucaran, J. Attal

\section{To cite this version:}

C. Chapus, F. Augereau, J. Podlecki, Gaëtan Lévêque, A. Foucaran, et al.. Carrier lifetime influence on clamped silicon wafer resonance by PTA effect. European Physical Journal: Applied Physics, 2010, 50 (3), pp.30301. 10.1051/epjap/2010054 . hal-00586474

\section{HAL Id: hal-00586474 https://hal.science/hal-00586474}

Submitted on 16 Apr 2011

HAL is a multi-disciplinary open access archive for the deposit and dissemination of scientific research documents, whether they are published or not. The documents may come from teaching and research institutions in France or abroad, or from public or private research centers.
L'archive ouverte pluridisciplinaire HAL, est destinée au dépôt et à la diffusion de documents scientifiques de niveau recherche, publiés ou non, émanant des établissements d'enseignement et de recherche français ou étrangers, des laboratoires publics ou privés. 


\title{
CARRIER LIFETIME INFLUENCE ON CLAMPED SILICON WAFER RESONANCE BY PTA EFFECT
}

\author{
Chapus C., Augereau F., Podlecki J., Lévêque G., Foucaran A., Attal J. \\ Laboratory IES (UMR CNRS 5214), University of Montpellier 2, Place Eugène Bataillon, F-34095 \\ Montpellier, France
}

PACS NUMBERS: 43.35.Ud, 43.40.Dx, 46.40.Ff, 46.40.-f, 85.30.-z (Photo acoustic effect, structural acoustic of membranes, resonance and damping of mechanical waves, vibration measurement, semiconductor devices)

\begin{abstract}
This experimental work presents reproducible measurement conditions to allow amplification of the mechanical vibration generated by photo-thermo-acoustics (PTA) effect using the resonance of circular Silicon membranes clamped by nitrile o-rings on a diameter of $30 \mathrm{~mm}\left(\mathrm{D}_{\mathrm{i}}\right)$. We use wafers with various thickness (h) between 250 and $1000 \mu \mathrm{m}$ and with carrier lifetime between 3 and $30 \mu \mathrm{s}$. Under the condition to have a resolution of few picometers for the measurement, it is possible to characterize the resonance mechanism obtained without contact by conventional laser vibrometry using a modulated laser diode of only a few milliwatts of power. Compared to perfect clamped membranes, the first Eigen frequency presents a downward shift of some hundreds Hertz due to the circular clamping by o-ring as predicted by our simplified model. The resonance frequency depends linearly on the thickness as long as $D_{i} / h>80$. The quality factor $(\mathrm{Q})$ does not exceed ten in agreement with our model for spring loaded membrane in air. The low value of quality factor and its variation according to thickness follow our predictions. Moreover, Q is independent of carrier lifetime whereas first resonance amplitude increases with it but less than prediction for bulks.
\end{abstract}

\section{INTRODUCTION}

Efficiency of photo-thermal effect to generate acoustic waves has been studied from a long time for bulk metallic materials, a chopped light leading to a mechanical vibration from thermo-elastic effect. The efficiency of the photo-acoustic effect is found to increase with the optical absorption coefficient and to decrease with the chopping frequency [1]. The photo-acoustic signal is affected by the total energy absorbed when $\mathrm{h}<\mu_{\mathrm{S}}$, with the $\mathrm{h}$ sample thickness and $\mu_{\mathrm{S}}$ the thermal diffusion length. Moreover, it has been demonstrated for aluminium samples that the acoustic strain amplitude is linearly proportional to the absorbed optical flux and also depends on the spot size [2].

For semiconductors, a periodic mechanical strain can be induced through fluctuations of the photo-generated free-carrier density [3]. In this mechanism, the excess carrier lifetime $\tau$ hasn't to be taken into account if $\omega \tau \gg 1$ with $\omega$ the optic angular frequency. Carrier thermalization and bulk recombination process generate electronic strain with specific frequency dependences and thermal diffusion process has also to be taken into account to study photo-acoustic efficiency [4,5]. From all these mechanisms, carrier transport characteristics of semiconductors have been studied using gas-microphone photo-acoustic cell [57], beam deflection [4] or piezoelectric detection [8]. Imaging of doping regions in silicon has been also obtained by scanning electron acoustic microscopy $[9,10]$. Nevertheless, the amplitude of the acoustic strain is generally reported in these studies in arbitrary units. So, it is difficult to figure out how small is the strength of this photo-acoustic phenomenon.

A possible means to amplify the photo-acoustic signal is to create a resonant structure. Silicon has been already used to build electrically driven thin diaphragms with very high $\mathrm{Q}$ factor as high as $2.10^{4}$ when operating in a vacuum system [11]. With these rigid clamping configuration and specific design, the Qfactor of etched resonant structure as MEMS may exceed nowadays $1.10^{5}$ in vacuum $[12,13]$. For macroscopic membranes, silicon wafers could be used but rigid clamping is somewhat difficult to realize due to the relative brittleness of thin crystalline plates. For this reason, we have investigated the effectiveness of polymer o-ring to clamp circular wafers to build resonators photo-excited by a laser diode and characterised in transmission configuration with a commercial laser Doppler velocimeter. Working at atmospheric pressure, mounting loss will be present depending on the membrane size and this could be a effect preponderant compared to air damping as computed for micro-beam resonators [14]. Indeed, a $10 \mu \mathrm{m}$ 
Silicon membrane clamped with diameters of several millimetres has given quality factor of the order of tens [15]. The vibration amplitude has not been measured but the authors have theoretically estimated it around 20pm. The photo-acoustic efficiency of our clamped system could be improved by the correct choice of the membrane size and doping. For Silicon, the best efficiency of the PTA effect is obtained for wavelength around 800nm [7].

To evaluate membrane size effect, we will test wafers with a radius of $14.05 \mathrm{~mm}$ and different thickness from 250 to $1000 \mu \mathrm{m}$. In the same way, the impact of clamping conditions and the effect of carrier lifetime will be investigated.

\section{THEORY}

To optimize the photo-acoustic efficiency of our silicon membranes, we have first calculated the dependence of photo induced acoustic vibration at the sample rear face $[16,4,17]$ using the following parameters.

\begin{tabular}{|l|l|l|l|l|l|l|l|}
\hline $\begin{array}{l}\text { Mass } \\
\text { density }\end{array}$ & $\begin{array}{l}\text { Young's } \\
\text { modulus }\end{array}$ & $\begin{array}{l}\text { Poisson } \\
\text { ratio }\end{array}$ & $\begin{array}{l}\text { Energy } \\
\text { gap }\end{array}$ & $\begin{array}{l}\text { Optic } \\
\text { absorption } \\
(\lambda=785 \mathrm{~nm})\end{array}$ & $\begin{array}{l}\text { Surface } \\
\text { recombination } \\
\text { velocity }\end{array}$ & $\begin{array}{l}\text { Thermal } \\
\text { diffusion length }\end{array}$ & $\begin{array}{l}\text { Thermal } \\
\text { diffusivity }\end{array}$ \\
\hline $2330 \mathrm{~kg} \cdot \mathrm{m}^{-3}$ & $130 \mathrm{GPa}$ & 0.28 & $1.12 \mathrm{eV}$ & $1121 \mathrm{~cm}^{-1}$ & $450 \mathrm{~cm} \cdot \mathrm{s}^{-1}$ & $14 \mathrm{~cm}^{2} \cdot \mathrm{s}^{-1}$ & $0.8 \mathrm{~cm} \cdot \mathrm{s}^{-1}$ \\
\hline Light flux & $\begin{array}{l}\text { Linear thermal } \\
\text { expansion }\end{array}$ & $\begin{array}{l}\text { Longitudinal sound } \\
\text { velocity }\end{array}$ & $\begin{array}{l}\text { Photostriction } \\
\text { coefficient }\end{array}$ & $\begin{array}{l}\text { Thermal } \\
\text { conductivity }\end{array}$ & $\begin{array}{l}\text { Laser } \\
\text { wavelength }\end{array}$ \\
\hline $7 \mathrm{~W} . \mathrm{cm}^{-3}$ & $2.6 .10^{-6} \mathrm{C}^{-1}$ & $8445 \mathrm{~m} . \mathrm{s}^{-1}$ & $-9.5 .10^{-25} \mathrm{~J} \cdot \mathrm{Pa}^{-1}$ & $1.3 \mathrm{~W} \cdot \mathrm{cm}^{-1} \cdot \mathrm{K}^{-1}$ & $785 \mathrm{~nm}$ \\
\hline
\end{tabular}

Table 1: computation parameters used for Silicon

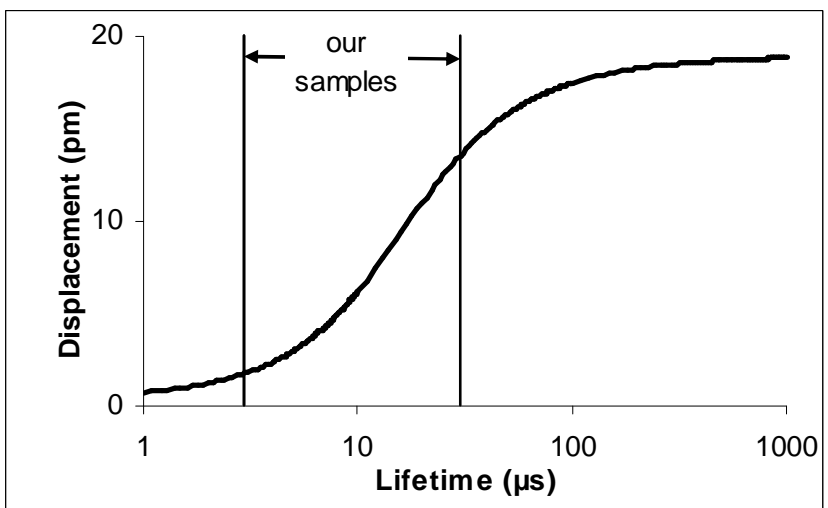

Figure 1: Theoretical displacement in $1 D$ model according to carrier lifetime for a bulk Silicon sample at $10 \mathrm{kHz}$

This simulation (figure 1), for a $287 \mu \mathrm{m}$ thick sample, is obtained from D. Marty-Dessus theory [16] and shows a photo-acoustic displacement increase versus carrier lifetime between 3 and $30 \mu$ s with a factor of 8 and then saturation occurs.

Another aim of this preliminary theoretical study was to investigate the effect of air damping and mounting loss on resonance characteristics. For this purpose, we have simulated the frequency response of a circular membrane in air (cf. table 1 for computation parameters) optically excited by a homogeneous light flux and clamped with circular o-rings considered as soft springs (cf. Appendix A).

\section{EXPERIMENTAL CONFIGURATION}

The experimental setup consists of an sinusoidal excitation laser, a sample holder and a laser vibrometer coupled to a lock-in amplifier (figure 2). The whole system is fixed on an optical bench (marble plate assembled on shock absorber) in order to limit external vibrations interferences. This experimental system is associated with a $\mathrm{x}-\mathrm{y}-\mathrm{z}$ stage in order to adjust the system alignment. 


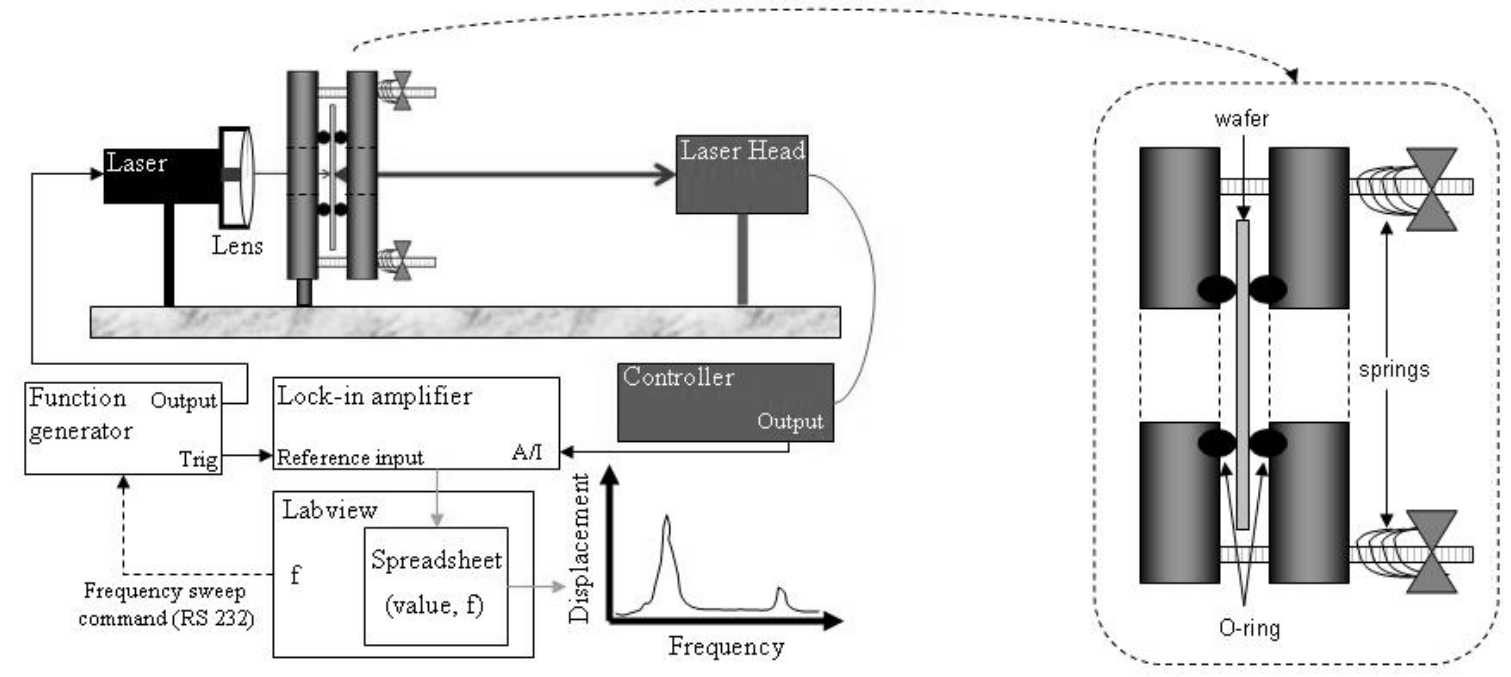

Figure 2: experimental setup for photo-acoustic signal detection in transmission configuration

The excitation laser used in this protocol (LQA 785-45C of NEWPORT) is analogically modulated and collimated. The principal characteristics are $785 \mathrm{~nm}+/-15 \mathrm{~nm}$ wavelength and a maximum optical power of $45 \mathrm{~mW}$. The modulation of the laser beam is carried out by a sinusoidal signal delivered by a function generator (Agilent 33250A). This laser is associated with a focusing optical system (convergent lens THORLABS with $6.16 \mathrm{~mm}$ focal distance and 0.30 numerical aperture) in order to maximize luminous flux.

Samples are circular wafers of Silicon clamped by two nitrile o-rings with an average radius of $14.05 \mathrm{~mm}$ tightened using two springs with a clamping force of $40 \mathrm{~N}$. This setup allows obtaining a good tightening reproducibility for each sample. The samples are wafers of two inches having thicknesses ranging between 250 and $1000 \mu \mathrm{m}$ and various doping (type $\mathrm{N}$ and $\mathrm{P}$, carrier lifetime between 3 and $30 \mu \mathrm{s}$ ). The carrier lifetime was controlled for each sample with a photoconductance carrier lifetime tester WCT120 of SINTON consulting.

For the acquisition of mechanical characteristics of vibrations, a vibrometer based on interferometry heterodyne and on the Doppler effect is used for the experimental setup. It is composed of a fiber-coupled vibrometer sensor head OFV 534 of Polytec coupled to a vibrometer controller OFV 5000 allowing measuring the speed and normal displacement in a range of frequencies active up to $30 \mathrm{MHz}$ with an ultimate resolution of $0.02 \mu \mathrm{m} / \mathrm{s}$ and $0.1 \mathrm{pm}$ respectively for velocity and displacement. To obtain a maximum signal on the detector, the sample is placed at distance of approximately $20 \mathrm{~cm}$ from the vibrometer.

Because the induced displacements by photo-thermo-acoustic effect can be very small $(<100 \mathrm{pm}$ cf. figure 2), it is necessary to extract the useful signal from the noise background. For this reason, we use a lock-in amplifier (STANDFORD RESEARCH SR830 DSP).

\section{RESULTS AND DISCUSSIONS}

The main goal of this study was to find the experimental conditions increasing the resonance of our semi-conductor clamped wafers. In order to determine the importance of the mechanical effects and semi conductor properties on the resonance phenomenon, we will study the characteristics of the first mode of resonance (resonance frequency, amplitude and factor of quality) according to the thickness of the membrane and to the carrier lifetime.

\section{1- Verification of resonance conditions}

With our experimental set up, we managed to have a resonance phenomenon which amplifies the Photo-Thermo-Acoustic (PTA) vibration. Nevertheless, the resonance displacement reaches only few tens of picometer and depends on the excitation optical power as shown in figure 3 , representing the amplitude of the first mode of resonance according to the incidental power for a Silicon wafer with $290 \mu \mathrm{m}$ thickness. Previous works on PTA effect [16] show that the resulting vibration in bulk materials is proportional to the excitation optical power. The same linear dependence is observed here. 


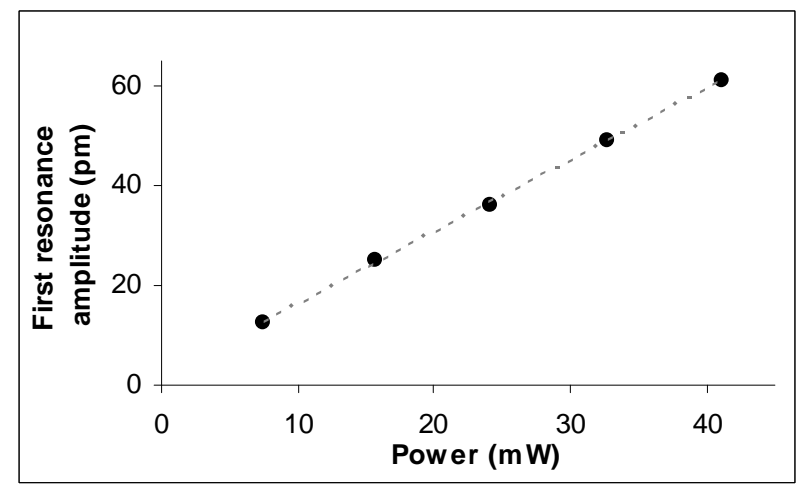

Figure 3: Amplitude of the first mode of resonance according to the incident power

For the resonance frequency, the theory of the clamped circular membranes [18] gives us the following frequencies:

$$
f_{01}=10.21 \frac{h}{2 \pi R^{2}} \sqrt{\frac{E}{12\left(1-v^{2}\right) \rho}} \text { and } f_{02}=39.77 \frac{h}{2 \pi R^{2}} \sqrt{\frac{E}{12\left(1-v^{2}\right) \rho}}
$$

where $h, \lambda_{m n}, R, E, \nu, \rho$ are respectively the thickness, a constant dependant on the vibrating mode, the radius, the Young's modulus, the Poisson's ratio and the mass density of the wafer.

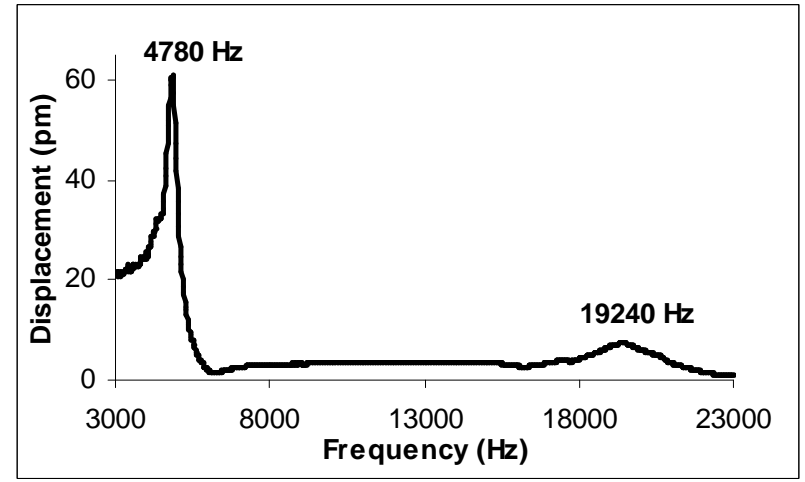

Figure 4: Example of experimental frequency response for a clamped wafer

In order to visualize only the modes of frequency $f_{01}$ and $f_{02}$, the excitation and detection laser will target the membrane centre. In figure 4, representing a typical frequency response of one of our clamped silicon wafers of $290 \mu \mathrm{m}$ thickness, we observe the two first modes without any parasitic modes. Moreover, the measured ratio $f_{01} / f_{02}$ is 4.02 while it should be of 3.89 in theory, indicating an error of $3 \%$. This small difference could be due to the unperfected clamping of the wafer.

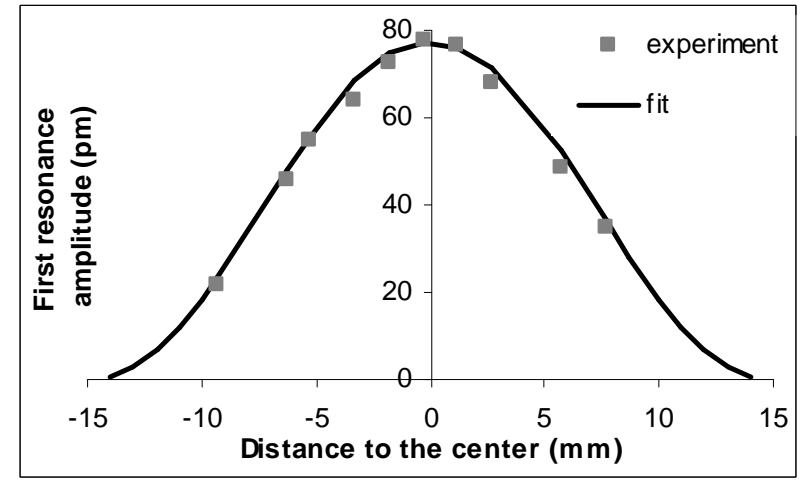

Figure 5: First mode of resonance deformation for the clamped circular wafer

Figure 5 shows the membrane profile deformation along a diameter for the first mode of resonance. The deformation shape is in agreement with the theory [18]. 


\section{2- Influence of carrier lifetime}

In order to evaluate the influence of $\tau$, a set of 45 Silicon wafers of different thickness and carrier lifetime was characterized by their resonance properties. For each sample we measured the frequency, the quality factor and the amplitude of the first mode of resonance.
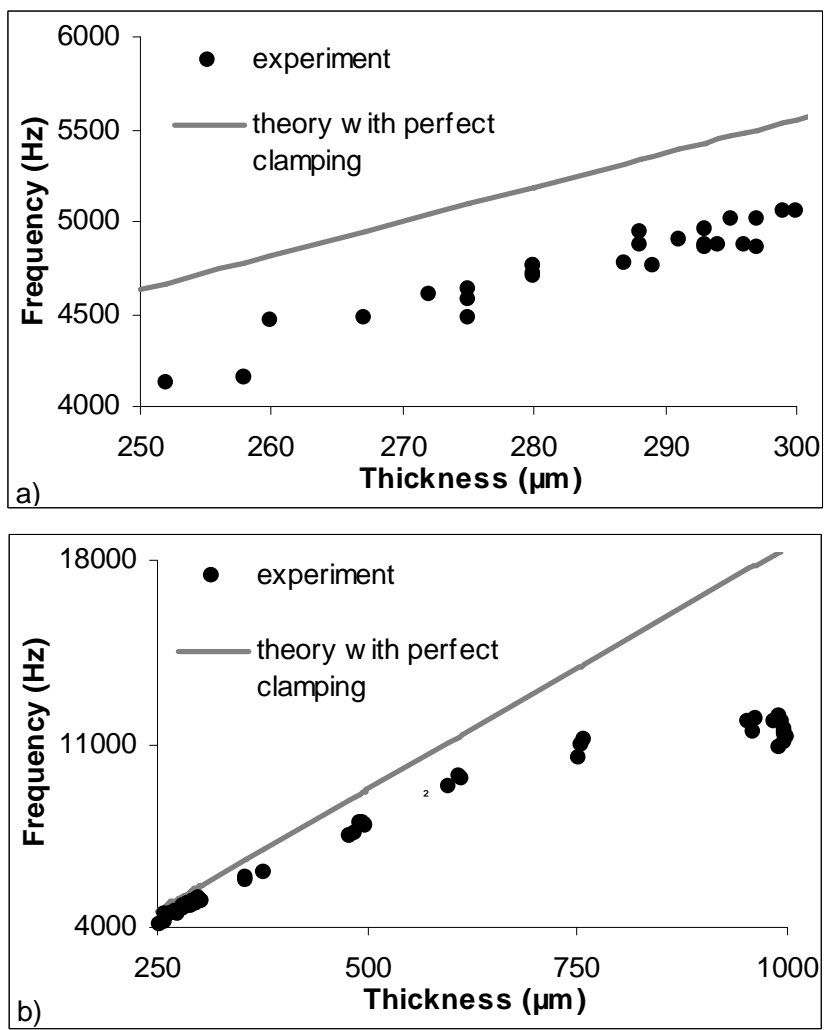

Figure 6: Experimental and theoretical frequency of the first resonance mode according to the thickness of wafer for a) thin wafers and $b$ ) all the wafers

The measured resonance frequencies are lower that theoretical ones (figure 6a). This difference of $500 \mathrm{~Hz}$ might be due to the non rigid clamping as show by our simulation results (figure A.1). However, these points show the same linear dependence. Moreover, the scattering of measurements can be explained by the uncertainties values taken and not by the semiconductor characteristics (doping and carrier lifetime). Indeed, for a $2 \%$ error on thickness $(\sim 5 \mu \mathrm{m}), 2 \%$ on radius $(14.05 \pm 0.3 \mathrm{~mm}), 5 \%$ on Young's modulus $(130 \pm 1 \mathrm{GPa})$ and $1 \%$ on Poisson's ratio $(0.28 \pm 0.01)$, the cumulative error is $300 \mathrm{~Hz}$.

As expected (cf. figure $6 \mathrm{~b}$ ), the more the thickness increases, the more the experiment deviates from the theory. This is because the membrane clamped assumption is no longer valid. Indeed, for these points the $D_{i} / \mathrm{h}$ ratio is lower than 80 which is the limit for membrane hypothesis [15].

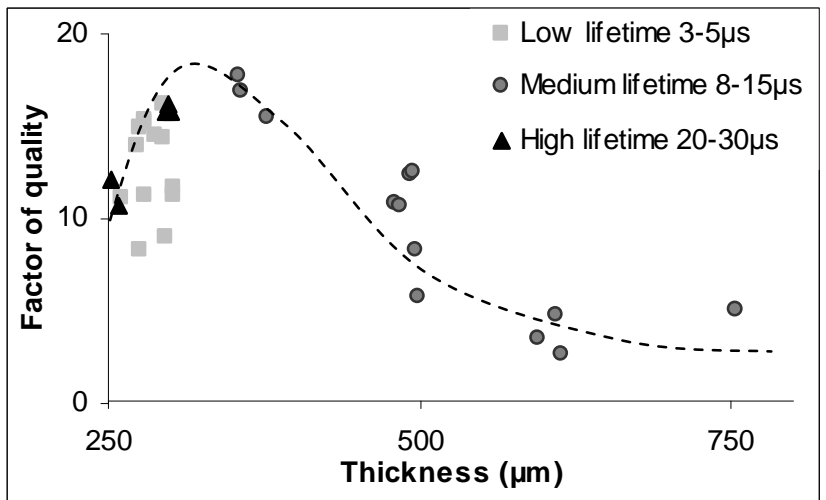

Figure 7: Quality factor of the first mode according to thickness

On figures 7 and 8 , only for thickness $<300 \mu \mathrm{m}$, experimental points with low and high carrier lifetime are represented with different markers. It shows the influence of thickness and carrier lifetime on the quality factor. The maximum value is around ten that is similar to our simulation for a spring loaded 
membrane in air. The dependence in thickness is in agreement with the model (figure A.2) but we can observe that for the samples with low thickness $(250<\mathrm{h}<300 \mu \mathrm{m})$ the $\mathrm{Q}$ factor is independent of carrier lifetime. This phenomenon is may be due to the predominant influence of the clamping which actually reduces the Q factor (figure A.1). So, with our experiment set up, doping influence on Q-factor isn't observable.

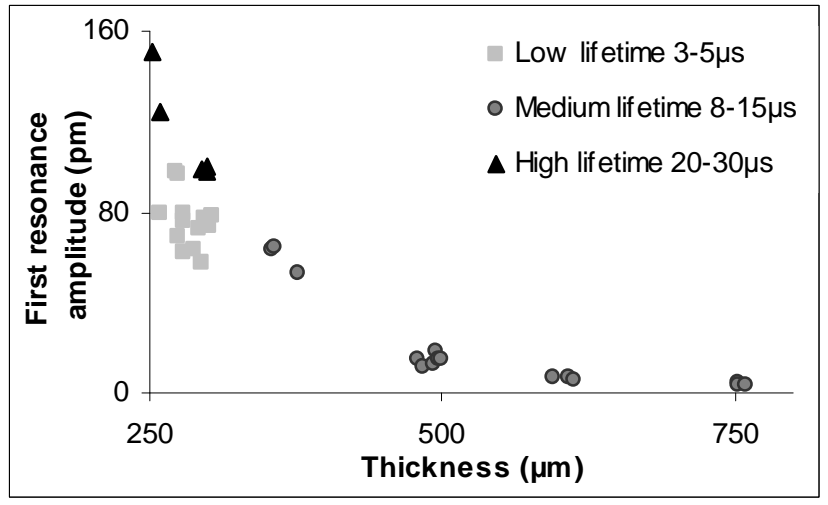

Figure 8: Amplitude of the first mode of resonance according to thickness

Figure 8 shows the decrease of the resonance amplitude according to the increase thickness of the wafer. Moreover, for low thickness we can see that the carrier lifetime influences the value of amplitude unlike Q-factor. For example, for a thickness of $250 \mu \mathrm{m}$ and identical clamping conditions, the Q-factor is around 10 for low and high carrier lifetime values while the first resonance amplitude is $80 \mathrm{pm}$ for $4 \mu \mathrm{s}$ carrier lifetime and is $130 \mathrm{pm}$ for $25 \mu \mathrm{s}$ carrier lifetime. So, for this lifetime range the first resonance amplitude is increased by a factor of two compared to a factor of eight obtained from simulation on Silicon bulk materials (figure 1).

We noticed during our tests that the type of doping did not change the results.

\section{CONCLUSION}

The experimental setup proposed in this study allowed us to detect the vibration amplification of a circular Silicon membrane clamped by toroidal o-rings and excited by a modulated laser diode of low power $(<45 \mathrm{~mW})$, using optical detection by conventional Doppler laser vibrometry.

The resonance frequency is lower than theoretical one calculated for a perfect clamped membrane but follows the same thickness dependence. This effect has been explained by spring loading and air damping in agreement with our simplified model. This also explains the low value of quality factor (around ten instead $10^{5}$ for Silicon in vacuum) and the dependence of Q-factor according to the thickness of the membrane.

Regarding the influence of the carrier lifetime in the range of 3 to $30 \mu$ s, our experiments show that Q-factor isn't modified whereas the amplitude of the first resonance mode increases with the carrier lifetime but with smaller variations compared to bulk materials.

\section{Appendix A}

In our simplified model, we consider a circular membrane in air optically excited by a homogeneous light flux and clamped with circular o-rings considered as soft springs. These assumptions, more or less close to experimental reality, allow qualitatively visualizing the main effects.

The equation of dynamics [19] is then written as:

$$
\left(\Delta^{2}-k^{4}\right) W(r)=P_{\text {laser }}
$$

with $P_{\text {laser }}$ the equivalent pressure applied by the laser flux, $W(r)$ the radial displacement component and $k$ the wave number.

$k^{4}=\frac{\rho h \omega^{2}+j \omega Z_{a i r}}{D}$

including the effect of air via $Z_{\text {air }}$ taken as the gas impedance on a piston [20] and with $\rho$ the sample mass density and $h$ the thickness of wafer and $\mathrm{D}$ the membrane flexural rigidity. 


$$
D=\frac{E h^{3}}{12\left(1-v^{2}\right)}
$$

with $E$ the Young's modulus and $v$ the Poisson's ratio of the wafer.

The solution of equation (A.1) for the asymmetric radial modes is:

$$
W(r)=F J_{0}(k r)+G I_{0}(k r)-\frac{P_{\text {laser }}}{D k^{4}}
$$

where $J_{0}$ is Bessel function of order one and $I_{0}$ modified Bessel function of order one.

$F$ et $G$ are constants depending on the limit conditions of the wafer. Boundary conditions are:

for a rigid clamping: $\left\{\begin{array}{l}W(R)=0 \\ \left.\frac{\partial W}{\partial r}\right|_{r=R}=0\end{array}\right.$ and for the o-ring: $\left\{\begin{array}{c}-Q_{r}(R) 2 \pi h=k_{\text {spring }} W(R) \\ \left.\frac{\partial W}{\partial r}\right|_{r=R}=0\end{array}\right.$

with $k_{\text {spring }}=k_{1}+j k_{2}$ the complex spring stiffness and $Q_{r}$ the shear stress on the membrane [19].

From this simplified model, the displacement amplitude at the centre of the membrane exhibits a resonance response versus frequency (cf. figure A.1). For this simulation $\mathrm{R}=14.05 \mathrm{~mm}$ radius and $\mathrm{h}=377 \mu \mathrm{m}$.

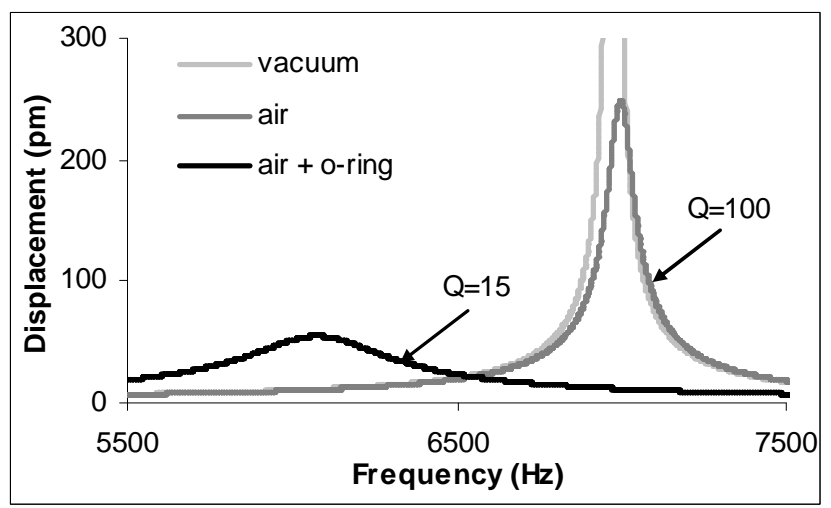

Figure A.1: Theoretical effects of air damping and viscous loss on the resonance response

The perfect clamping system in air gives a Q-factor around 100. For a clamping with nitrile o-ring, Q- factor decreases to 15 . We also observe that the elastic clamping induces a large decrease of the resonance frequency. The mounting loss seems to be a very limiting factor for Q.

This model also allows seeing the evolution of Q-factor according to the thickness (figure A.2) with all other parameters unchanged. It shows a maximum value that could be explained by the combined effect of air damping and mounting loss.

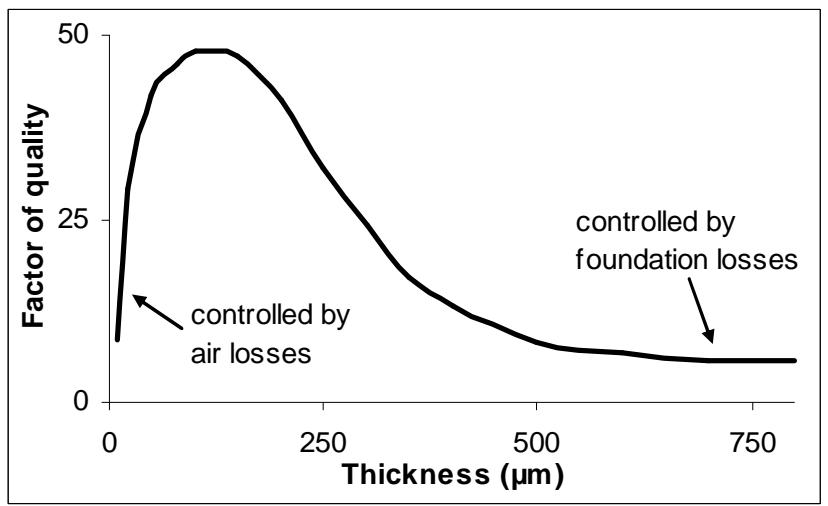

Figure A.2: Theoretical of Q-factor according to membrane thickness

\section{REFERENCES}

1. F. A. Mc Donald, G. C. Wetsel Jr, J. Appl. Phys., 49, 2313-2322 (1978)

2. W. Arnold, B. Betz, B. Hoffman, Appl. Phys. Lett., 47, 672-674 (1985)

3. R. G. Stearns and G. S. Kino, Applied Physics Letters, 47, 1048-1050 (1985)

4. D. Fournier, C. Boccara, A. Skumanich, and N. M. Amer, Journal of Applied Physics 59, 787-795 (1986) 
5. D. M. Todorovic, P. M. Nikolic, A. I. Bojicic, K. T. Radulovic, Physical Review B, 55, 15631-15641 (1997)

6. A. Pinto Neto, H. Vergas, N. F. Leite, L. C. M. Miranda, Physical Review B, 41, 9971-9979 (1990)

7. H. Kuwahata, N. Muto, F.Uehara, Jpn. J. Appl. Phys., 39, 3169-3171 (2000)

8. D. A. Andrusenko, I. Ya. Kucherov, Technical Physics, 44, 1397-1401 (1999)

9. A. Rosencwaig, R. M. White, Appl. Phys. Lett., 38, 165-168 (1981)

10. N. Kultscher and L. J. Balk, Scanning Electron Microscopy IV, 33-43 (1986)

11. H. Guckel, S. Larsen, M. G. Lagally and al., Applied Physics Letters, 31, 618-619 (1977)

12. J. Frömel, D. Billep, T. Gessner, M. Wiener, Michrosyst Technol, 12, 481-483 (2006)

13. B. M. Zwickl, W. E. Shanks, A. M. Jayich and al., Apllied Physics Letters, 92, 103125-103125 (2008)

14. Y. Sun, D. Fang, A. K. Soh, International Journal of Solids and Structures, 43, 3213-3229 (2006)

15. E. Dieulesaint, D. Royer, and C. Bonnefoy, Ieee Transactions on Sonics and Ultrasonics, 29, 176-177 (1982).

16. D. Martydessus, M. E. Zejjari, N. Boughanmi, J. Boucher, and J. L. Franceschi, Journal De Physique III 2, 1509-1526 (1992)

17. H. Severac, M. Mousseigne, and J. L. Franceschi, Journal De Physique III, 6, 1451-1465 (1996)

18. M. Gerardin, D. Rixen, Théorie des vibrations, $2^{\text {nd }}$ edn (Masson, Paris, 1996)

19. E. Ventsel, T. Krauthammer, Thin Plates and Shells (Marcel Dekker, New York, 2001)

20. N. H. Fletcher, T. D. Rossing, The Physics of Musical Instruments, $2^{\text {nd }}$ edn (Springer-Verlag, New York, 2000) 